\title{
LA CRUZ DE SANTORCAZ (MADRID), UNA OBRA DESCONOCIDA DEL PLATERO COMPLUTENSE GASPAR DE GUZMÁN ${ }^{1}$
}

\author{
POR \\ $M^{a}$ DEL CARMEN HEREDIA MORENO \\ Universidad de Alcalá \\ AMELIA LÓPEZ-YARTO ELIZALDE
Departamento de Historia del Arte \\ (C.E.H.) (CSIC)
}

\begin{abstract}
This article studies a silver cross made by Gaspar de Guzman, a silversmith of Alcalá de Henares, in 1576. We also analyze its exceptional iconographic programe and we point to Sancho Busto de Villegas as its posible mentor.
\end{abstract}

En la exposición sobre orfebrería y ropas de culto, celebrada en el Museo Arqueológico Nacional de Madrid en el año 1941 con el propósito de que las instituciones religiosas españolas pudieran recuperar la parte de su patrimonio artístico salvado tras la contienda civil de 1936, figuraba una interesante cruz parroquial de procedencia desconocida que nunca fue reclamada ${ }^{2}$. La documentación de la pieza, tanto las fotografías de conjunto y detalles como una extensa ficha que incluía la descripción detallada de la misma y su cronología aproximada en torno a 1580, fue cedida, tras la muestra, al Instituto Diego Velázquez del CSIC donde hoy se guarda. Sin embargo, las fotos han pasado desapercibidas para los estudiosos de la platería española (Figs. 1-2).

Hace unos meses, al revisar el archivo fotográfico, no sólo advertimos su innegable parentesco con obras complutenses contemporáneas del círculo de Gaspar de Guzmán, sino que también nos llamó la atención su calidad y, sobre todo, su peculiar iconografía que la convierte en ejemplar único y singular en el contexto de la platería española de la segunda mitad del siglo XVI. Todo ello pese a que su evidente deterioro y a que las mutilaciones de los extremos de los brazos hacen difícil la reconstrucción completa de su programa primitivo.

En efecto, aparte del relieve de la esfera armilar representado en el anverso del cuadrón, la figura más llamativa es la imagen de San Torcuato que ocupa una posición preferente a los pies del Crucificado, hoy desaparecido, y que es el único santo identificado mediante una inscripción, en el conjunto de los siete reproducidos en los campos rectangulares del interior de los brazos de la cruz (Fig. 6). Parecía evidente que este protagonismo de San Torcuato había que

\footnotetext{
1 Este artículo forma parte del Proyecto de Investigación PS95-0033 aprobado por la DGICYT del Ministerio de Educación y Cultura.

2 E. Camps Cazorla: «Sección de orfebrería», Exposición de Orfebrería y Ropas de Culto, Madrid, 1941, sala III n ${ }^{\text {os }} 31$ ó 32 .
} 
N
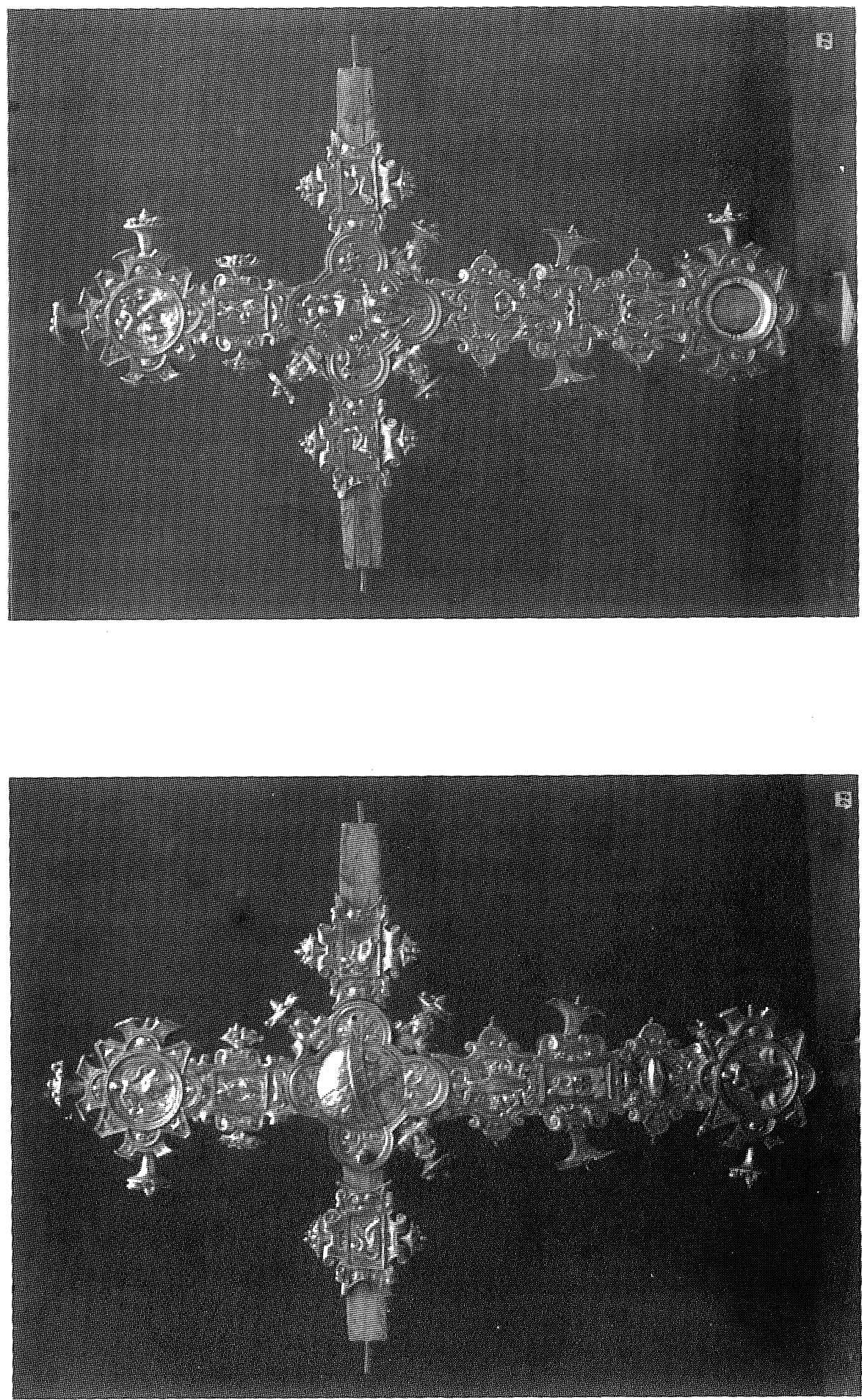

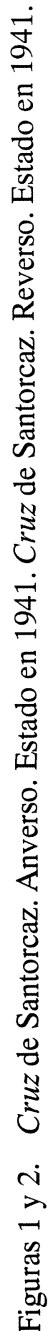


relacionarlo con la advocación concreta de la parroquia o con el lugar de procedencia de la obra. Por estos motivos dirigimos nuestra atención a Santorcaz, localidad próxima a Alcalá de Henares, probable lugar de origen de San Torcuato y única población cuya parroquia estaba dedicada al santo en el territorio que hoy es la comunidad de Madrid y la provincia de Guadalajara, es decir en la zona geográfica que constituyó el ámbito natural de expansión de la platería complutense ${ }^{3}$. En su libro de fábrica consta documentalmente que en el año 1577 se pagaron a Gaspar de Guzmán treinta y dos mil quinientos maravedís que restaban de la hechura de la cruz ${ }^{4}$. Nuestra hipótesis fue confirmada además por el testimonio oral de algunos vecinos que reconocieron en las viejas fotos la antigua cruz de la parroquia, desde la guerra civil en paradero desconocido.

El paso siguiente fue inspeccionar los museos e instituciones por donde el Servicio de Recuperación Artística había distribuido las piezas no reclamadas en la mencionada exposición de 1941. Así logramos localizar, en la planta baja del Museo de Santa Cruz de Toledo, una cruz muy semejante aunque, al parecer, procedente de Algete y atribuida a Juan Rodríguez de Babia ${ }^{5}$. A pesar de que la pieza estaba completa y, en principio, parecía en perfecto estado de conservación, su análisis detallado y la comparación minuciosa con las fotografías antiguas revelaron, sin lugar a dudas, que se trata de la misma cruz tras haber sido sometida a una profunda restauración y reconstrucción de los remates perdidos, copiando en ellos la iconografía preexistente. Por este motivo, algunos de los relieves inscritos en los medallones circulares nuevos se repiten (Fig. 3). Es decir, creemos poder afirmar, con casi absoluta certeza, tanto por razones iconográficas, como por datos documentales y por el cotejo de la obra de plata con las imágenes antiguas, que el árbol de la cruz del Museo de Santa Cruz de Toledo es el encargo que la parroquia de Santorcaz (Madrid) hizo a Gaspar de Guzmán, platero complutense del siglo XVI, que terminó de cobrar su trabajo el día 18 de junio de 1577.

Respecto de la manzana correspondiente, existe hoy día en el Museo de Valladolid una pieza ingresada en el año 1941 y procedente también del Servicio de Recuperación Artística que, creemos, puede ser la de la cruz de Santorcaz (Fig. 4). Lleva marcas de Alcalá de Henares, de Castillo y de Gaspar de Guzmán ${ }^{6}$ y, en alguna ocasión, se ha citado como parte de la cruz de Trijueque (Guadalajara) cuyo árbol habría desaparecido ${ }^{7}$. Sin embargo existe una antigua fotografía del Archivo Camarillo que reproduce la auténtica cruz de Trijueque, completa, con una manzana distinta a la de Valladolid y que, según Herrera Casado, se conserva hoy día en el Museo Diocesano de Sigüenza ${ }^{8}$ (Fig. 5). Estas circunstancias y el hecho de que, según el estado actual de la investigación, no existan indicios documentales de otras cruces parroquiales de este artífice, salvo las ya conocidas de Bujalaro y Pioz, fechables en torno a 1570, o la de guión de Moratilla de los Meleros, labrada en 1573 y que sería de tamaño

${ }^{3}$ Según P. Suárez: Historia del Obispado de Guadix y Baza, Madrid, 1696, p. 64, todavía a finales del siglo XVII sólo existían en la Península unas pocas iglesias dedicadas a San Torcuato, entre ellas la del convento de monjas agustinas de Toledo, iglesia del monasterio de santa Coloma en Orense, jesuítas de Guadix o Zamora, además de la de Santorcaz.

APS. Libro $1^{\circ}$ de Fábricas y Memoria, 1563-1586 y 1590, fol. 14, 18 de junio de 1577.

Además de la catalogación en el propio museo, la menciona con esta atribución y procedencia J. M. Cruz Valdovinos: «Platería», en Historia de las Artes Aplicadas e Industriales en España, Madrid, 1982, p. 100.

6 La dio a conocer Brasas Egido: La platería vallisoletana y su difusión, Valladolid, 1980, p. 173 y fig. 227.

Así lo considera J. M. Cruz Valdovinos: «Platería...», p. 101.

Herrera Casado: «Orfebrería antigua de Guadalajara, (algunas notas para su estudio)», Wad-Al-Hayara, no 4, 1977, p. 23. Sin embargo hemos podido comprobar que la Cruz de Trijueque no se encuentra en Sigüenza. Sus únicos restos podrían ser un par de fragmentos calcinados que ingresaron en el Museo de Valladolid en 1941 y que son idénticos a la cruz del Archivo Camarillo. 

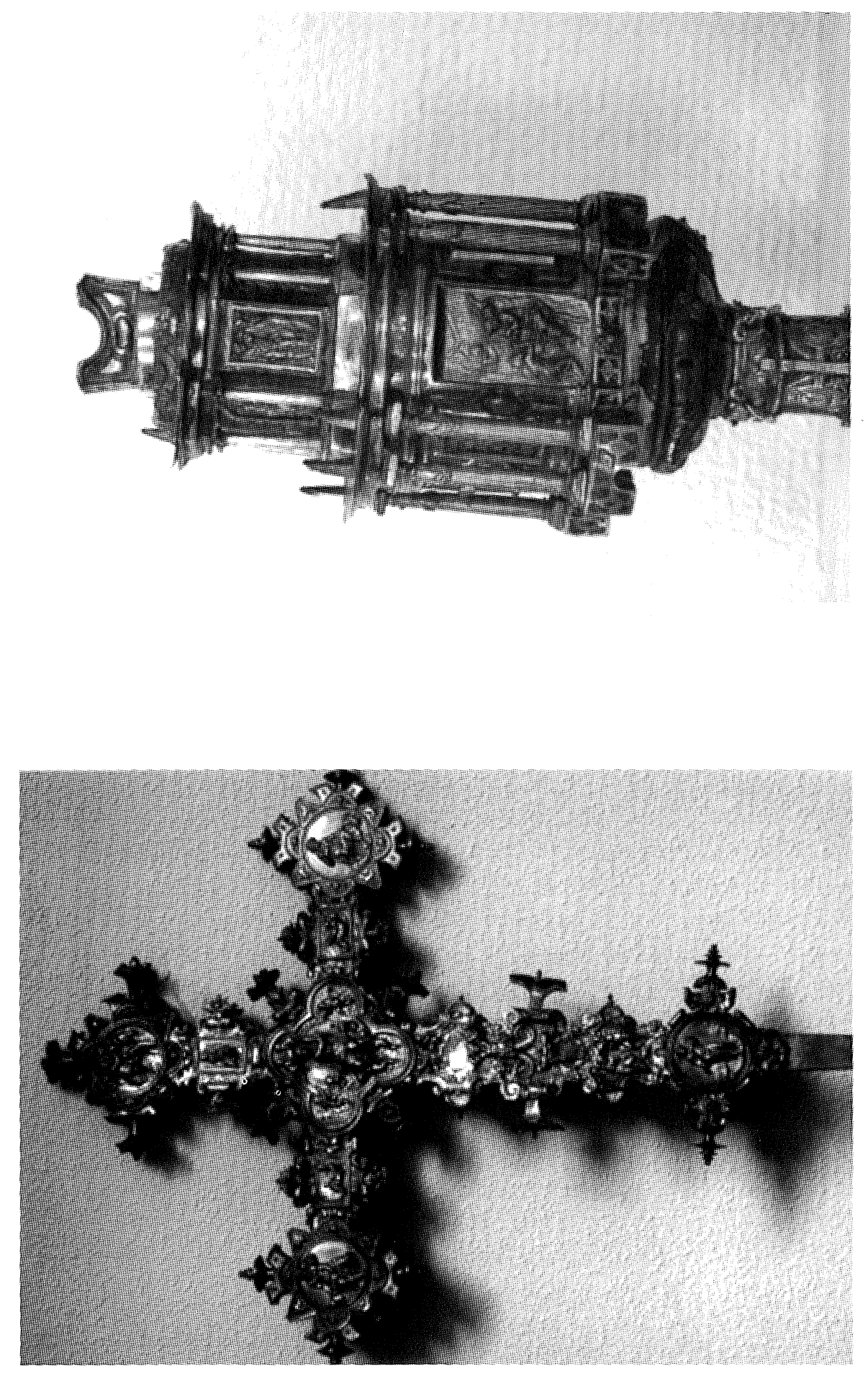

$\forall$

年

m $\begin{aligned} & m \\ & 0 \\ & 5 \\ & 5\end{aligned}$ 
más reducido, parecen confirmar nuestra hipótesis ${ }^{9}$.

Gaspar de Guzmán aparece citado con frecuencia en los documentos entre 1566 y 1571 en relación con hechuras de copas de comunión para diferentes poblaciones de los alrededores de Alcalá o con otras obras menores, como el vaso de plata de Escariche (1568) o los aderezos de la cruz de guión de Chiloeches (1569-1570) y de la parroquial de Meco (1569) ${ }^{10}$. Pero su actividad profesional debió de iniciarse en torno a 1560 y sus grandes piezas conservadas lo revelan como uno de los plateros complutenses más importantes de la segunda mitad del siglo XVI. El hecho de que en el año 1564 se encargue de cobrar la cruz de Pioz marcada por Antonio Faraz parece indicar que su formación tuvo lugar con este maestro, lo que explicaría la influencia de Faraz que se observa en sus primeras cruces. En efecto, el diseño de la de Pioz sirvió de modelo a Guzmán para la cruz parroquial que hoy se guarda en la parroquia de Bujalaro ${ }^{11}$ y que presenta los característicos ensanches en forma de media luna junto al cuadrón circular. Este esquema se vuelve a repetir en la cruz de Jirueque, obra quizás del mismo autor y fechable, como la anterior, en torno a 1570. Más adelante, hacia 1575, las cruces de Guzmán adoptan unos perfiles más recortados al incorporar cartelas correiformes, al tiempo que los relieves figurativos acentúan su carácter romanista y la iconografía adquiere mayor desarrollo. El cambio revela un acercamiento y un contacto directo con los trabajos del platero Marcos Hernández que, ya en su cruz de Valdeavero, labrada en $1569^{12}$, había introducido novedades sustanciales, inspiradas en grabados europeos y en la retablística hispana contemporánea. En cualquier caso, los años setenta constituyeron los de madurez para Gaspar de Guzmán y fue en la cruz de Santorcaz que terminaba de cobrar en 1577 donde introdujo este nuevo lenguaje. Paralelamente, el platero ejecutaba también las custodias de El Casar de Talamanca (1576-1580) y de la catedral de Sigüenza. Esta fue, quizás, su última obra ya que se supone que falleció poco después, hacia 1584.

La cruz de Santorcaz consta de cuadrón cuadrilobulado y brazos de perfil mixtilíneo con rectángulos interiores y remates circulares, contorneados todos ellos por cintas de cartelas que culminan en cestillos acampanados con frutos. Los que rodean al cuadrón, más complejos, están sujetos por conchas y cabezas veladas. Parejas de desnudos infantiles, erguidos o sedentes, además de figuras de atlantes se reparten por el resto de la superficie del brazo vertical.

A los rectángulos de los brazos se ajustan relieves de siete santos, en pie o reclinados para adaptarse al formato vertical u horizontal de los mismos. Entre ellos se reconoce a San Torcuato por la inscripción que hay bajo sus pies (Fig. 6). El resto carece de atributos iconográficos claros, salvo los ropajes e insignias episcopales. No obstante, teniendo en cuenta que S. Torcuato fue el primero de los Siete Varones Apostólicos que, según la tradición,

\footnotetext{
9 La de Pioz lleva marcas de Antonio Faraz aunque los pagos se hacen a Gaspar de Guzmán, según recogió J. M. Cruz Valdovinos: Los Faraces, plateros complutenses del siglo XVI, Alcalá de Henares, 1988, p. 149. La de Moratilla de los Meleros la menciona este mismo autor en «Platería madrileña del siglo XVI», Madrid en el Renacimiento, Madrid, 1986, p. 260. Recientemente, N. Esteban: «La platería de Jirueque», Actas del IV Encuentro de Historiadores del Valle del Henares, 1994, p. 500 publicó la cruz de Jirueque relacionándola con el círculo de Antonio Faraz. Quizás habría que considerarla también obra complutense del propio Gaspar de Guzmán.

${ }_{10}$ Los arreglos en las cruces son datos inéditos procedentes del APCH. Libro de Fábricas (1521-1613), diciembre de 1566 y mayo de 1570 y APM. Libro de Fábricas desde 1569 a 1620, año de 1569, en que también ejecuta un vaso de comunión.

11 Es de procedencia desconocida. La primitiva cruz de Bujalaro, según fotografía del archivo Camarillo recogida por Layna Serrano: La provincia de Guadalajara, Guadalajara, 1948, p. 304, es una pieza del siglo XVI, actualmente en paradero desconocido.

12 APV. $2^{\circ}$ Libro de Fabrica (1562-1582). En la relación de pagos de 1569 se le libran 27.270 maravedís a cuenta de la cruz.
} 
fueron convertidos al cristianismo por el apóstol Santiago y, tras su posterior consagración por San Pedro, enviados a España donde fundaron las primeras sedes episcopales, sospechamos que las figuras reproduzcan a estos personajes ${ }^{13}$. La elección de esta iconografía tan poco frecuente en la retablística y en la pintura contemporánea, y por completo excepcional en las obras de platería, obedece a que, entre las diversas opiniones sobre el lugar de nacimiento de San Torcuato, la más difundida lo hace natural de Santorcaz que, en el siglo XVI, dependía directamente del Señorío Episcopal de Toledo ${ }^{14}$. Y fue precisamente el cardenal Gaspar de Quiroga quien, pocos años después de la ejecución de la cruz, concedió el patronazgo de este santo a la población y su titularidad a su iglesia parroquial en $1583^{15}$. Este suceso demuestra el clima de reivindicación de la figura de San Torcuato y el conocimiento de su historia que existía en su lugar de nacimiento y en el arzobispado de Toledo por estas fechas. El octavo rectángulo, situado a los pies de la Asunción-Coronación de la Virgen, sustituye la representación figurativa por una inscripción con la leyenda «...ON/ET/ORI/GO/BON/OR/VM» ${ }^{16}$.

Respecto a los medallones circulares, sólo quedan de los relieves primitivos las figuras de san Juan evangelista y la Virgen, en el anverso del brazo vertical, y la escena de la Imposición de la casulla a San Ildefonso (Fig. 7), en el reverso del mismo, todos ellos descolocados hoy de su emplazamiento primitivo. Este último tema hace referencia a una devoción de fuerte arraigo en la archidiócesis toledana, mientras que San Juan y la Virgen formarían parte del grupo de los evangelistas y del Calvario, respectivamente. El resto de los tondos fueron añadidos en una reciente restauración posterior a su ingreso en el museo de Santa Cruz y reproducen las figuras de San Lucas y San Juan Bautista, repetidas dos veces, así como la de la Virgen que repite, a su vez, la primitiva ${ }^{17}$.

En el reverso del cuadrón se representa la escena de la Asunción-Coronación de la Virgen entre nubes y ángeles niños desnudos, hábilmente dispuestos en el interior de los lóbulos (Fig. 8). Este relieve es de acusado carácter romanista y sigue en la figura de María, aunque invertido, el esquema de la cruz de Valdeavero que Marcos Hernández había labrado unos años atrás. Por otra parte, su semejanza con la Asunción-Coronación del retablo de Astorga ejecutado por Gaspar Becerra en 1558 permite suponer que el platero complutense conocía la obra del escultor andaluz (Fig. 9), si no ésta de Astorga sí el retablo de las Descalzas Reales que Becerra había realizado en Madrid entre 1562 y 1563 por encargo de doña Juana de Austria, la hija del emperador Carlos $\mathrm{V}^{18}$. En ambos relieves la composición es muy seme-

13 Sobre los Siete Varones Apostólicos véase, además de P. Suárez: Historia..., J. Vives: «Varones Apostólicos» en Diccionario de Historia Eclesiástica de España, T. VI, Madrid, 1972, p. 2.715. Sus nombres y sedes son: Torcuato, de Acci (Guadix); Tesifonte, de Bergium (Berja); Esicio, de Cárcer (Carcesa); Indalecio, de Urci (Almería); Segundo, de Abula (Ávila); Eufrasio, de Iliturgi (Andújar) y Cecilio, de Illiberis (Elvira).

14 A. Alvar Ezquerra: «Madrid en el siglo XVI: Entre el anacronismo y la realidad», en Madrid en el Renacimiento, Madrid, 1986, p. 11.

15 P. Suárez: Historia..., p. 21. También recoge antiguas tradiciones sobre la biografía de San Torcuato Portilla y Esquivel: Historia de la ciudad de Compluto, Alcalá, 1725, p. 75.

16 La inscripción está incompleta y pensamos que la lectura correcta podría ser «Fons et origo bonorum».

17 Según noticias facilitadas por el personal del museo, a quien agradecemos su colaboración, la cruz fue restaurada por Julio Pascual, rejero toledano, que reconstruyó el reverso horizontal izquierdo y las placas perdidas. Además conserva el museo una fotografía anterior a la restauración en la que figura un medallón de San Juan Evangelista que no coincide con el actual.

${ }_{18}$ Un dibujo del desaparecido retablo de Las Descalzas es reproducido por F. Fabre: «El altar mayor de las Descalzas Reales», en Semanario Pintoresco Español, 1839, p. 161. También se conserva el dibujo original de Becerra para la mazonería del retablo. Lo recoge A. E. Pérez Sánchez: El dibujo español de los siglos de oro, Madrid, 1980, $\mathrm{n}^{\mathrm{o}} 2$. Además hay que tener en cuenta que Becerra estuvo en Toledo en 1563 y en 1569 pintando en la catedral, según recogen F. Pérez Sedano: «Notas del archivo de la catedral de Toledo», Madrid, 1914, pp. 12 y 130, y M. Zarco del Valle: «Documentos de la catedral de Toledo», Madrid, 1916, pp. 113 y 139, ambos en Datos documentales inéditos para la Historia del Arte Español. 

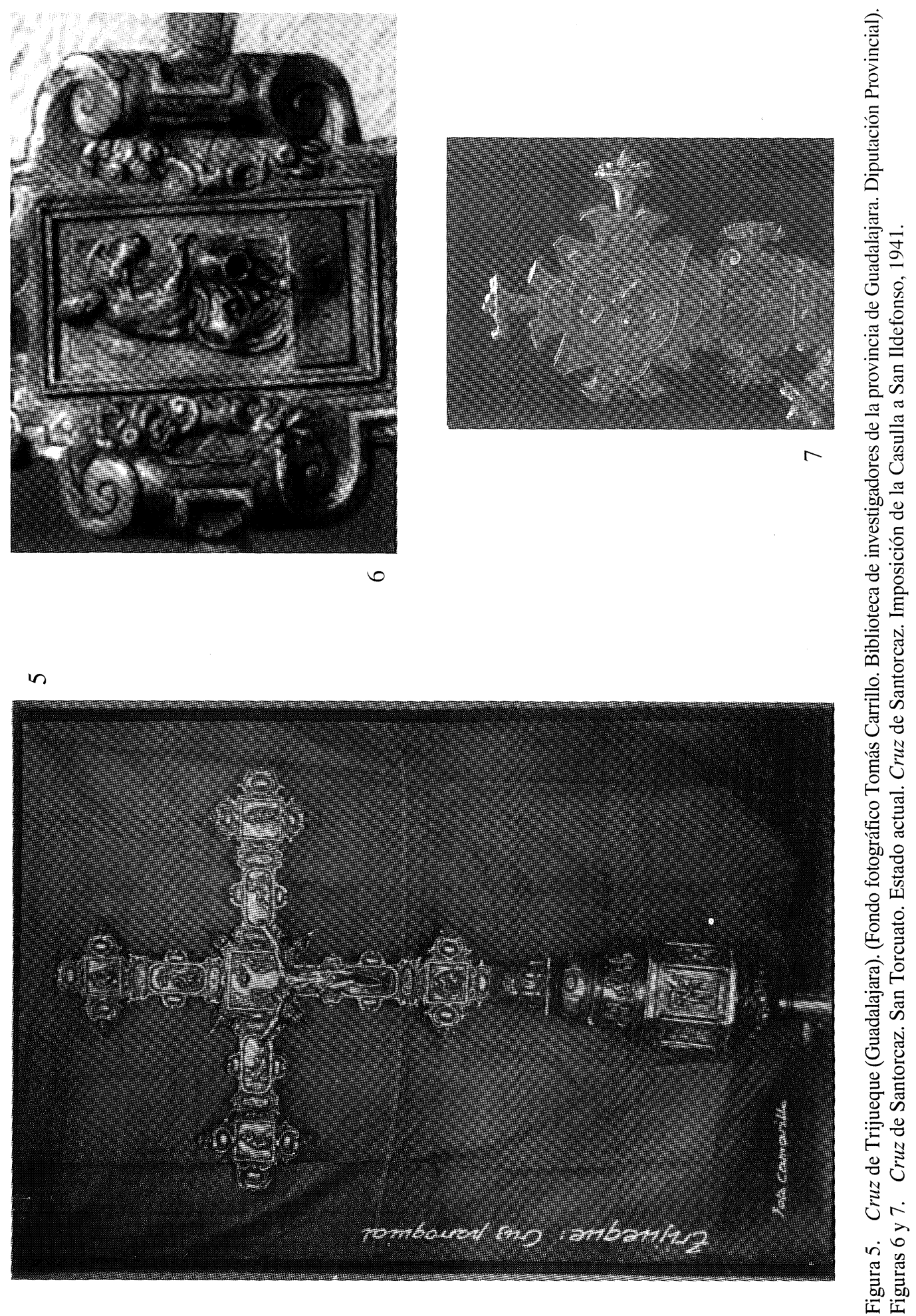
jante y está inspirada, a su vez, igual que la del posterior retablo de Briviesca, en la Asunción que Daniel de Volterra había pintado en la capilla Della Rovere de la iglesia romana de la Trinitá dei Monti ${ }^{19}$. Las diferencias accidentales que se observan en la pieza de plata son las imprescindibles para la correcta adaptación del tema desde el formato rectangular del retablo al marco polilobulado de la cruz.

Sin embargo, el relieve más interesante, tanto por su carácter excepcional en toda la platería española cuanto por su significado, es, sin lugar a dudas, el de la esfera armilar con los signos del zodíaco reproducido en el anverso del cuadrón (Fig. 10). Lleva la inscripción «MORS MEA VITA VESTRA» e incluye las representaciones del Sol y la Luna, el Ecuador celeste y la Eclíptica con los signos de Libra, Escorpión y Piscis. No debió de resultar difícil para Guzmán encontrar un modelo en qué inspirarse, ya que la esfera armilar fue un objeto muy difundido a partir del siglo XV y a lo largo del XVI a través de estampas sueltas o impresas en libros sobre astrología. Aparte de las conocidas imágenes de Durero, la primera de las cuales data de $1503^{20}$, existen numerosas obras editadas en Nuremberg, Viena y otras muchas localidades europeas ${ }^{21}$. El famoso Opusculum de Sphera Mundi o Tratado de la Esfera, de Juan de Sacrobosco, por ejemplo, alcanzó no menos de once ediciones, una de las cuales fue la que efectuó el impresor Miguel de Eguía en Alcalá de Henares en 1526 según la versión de Pedro Ciruelo ${ }^{22}$ (Fig. 11).

Pero no creemos que el relieve de Santorcaz sea una simple reproducción formal de una estampa copiada de un tratado de astrología. La elección y la ordenación de los elementos evidencian una intencionalidad clara por parte del mentor de la obra ${ }^{23}$. Se trata de representar un horóscopo que, en el contexto de una cruz parroquial, no puede ser otro que el de la muerte de Cristo, apoyado, quizás, en el conocimiento del horóscopo de Cardan publicado en Basilea en $1554{ }^{24}$. No se trataría de un caso aislado puesto que la obra del astrólogo sirvió de inspiración directa para sendos horóscopos de Cristo representados con escasa diferencia de años en la tabla de la «Sagrada Familia» de la Hispanic Society of New York, que Luis de Morales pintó hacia 1563 para el obispo de Badajoz Juan de Ribera, o en el arco de ingreso de Santa María de Viana (Navarra), labrado por el escultor Juan de Ochoa Arranotegui hacia 1555 bajo los auspicios del obispo de Calahorra-Logroño-La Cạlzada don Juan Bernal Díaz de Luco $^{25}$.

19 M. Calí: De Miguel Ángel a El Escorial. Momentos del debate religioso en el arte del siglo XVI, Madrid, 1994, p. 238 y fig. 36. A. Barrón y M. P. Ruíz de la Cuesta: «Notas sobre el retablo de Santa Clara de Briviesca», Archivo Español de Arte, nº 279, 1997, p. 258 ya relacionaron la obra de Volterra con este retablo.

${ }^{20}$ Se trata del desnudo femenino con la esfera del Zodíaco que reproduce Hollstein: German engravings etchings and woodcuts (1400-1470), Amsterdam, vol. VII, p. 209.

${ }_{21}$ Algunas se recogieron en el Catálogo de la Exposición sobre Grabados Alemanes en la Biblioteca Nacional, Madrid, 1997, $\mathrm{n}^{\text {os }}$. 18, 758, 759, 760, 989, 1099 y 1124.

${ }_{22}$ Lo recoge J. Martín Abad: La imprenta en Alcalá de Henares, 1502-1600, Madrid, 1991, p. 81. M. A. Santos Quer: «Opusculum de Sphera Mundi: Importancia y análisis de sus imágenes en distintas ediciones», IV Encuentro de Historiadores del Valle del Henares, 1994, pp. 675 y ss. ha comentado sus distintas ediciones.

${ }_{23}$ Desde el primer momento nos pareció evidente que se trataba de la representación del horóscopo de la muerte de Cristo, pero para su correcta interpretación hemos seguido las precisas y oportunas indicaciones del profesor Juan Francisco Esteban Lorente a quien expresamos nuestro más sincero agradecimiento.

${ }^{24}$ J. Cardan: In Cl.Ptolemaiei pelusiensis IIII de Astrorum iudiciis, aut, vulgo vocant Quadripartitae constitucionis, libros comentaria...Eiusdem Hier Cardani geniturarum XII..., Basilea, Henrichus Petri, marzo de 1554, p. 164. Recogido por J. F. Esteban Lorente en los artículos citados en la nota 25.

${ }_{25}$ Ambas obras han sido interpretadas recientemente por J. F. Esteban Lorente: «La Naturaleza Humana de Cristo, por Luis de Morales», Don Antonio Durán Gudiol. Homenaje, Huesca, 1995, pp. 253-266 y «El arco de ingreso de la colegiata de Santa María de Viana. Horóscopos de Cristo», Berceo, 1996, nº 130, pp. 19-41. 

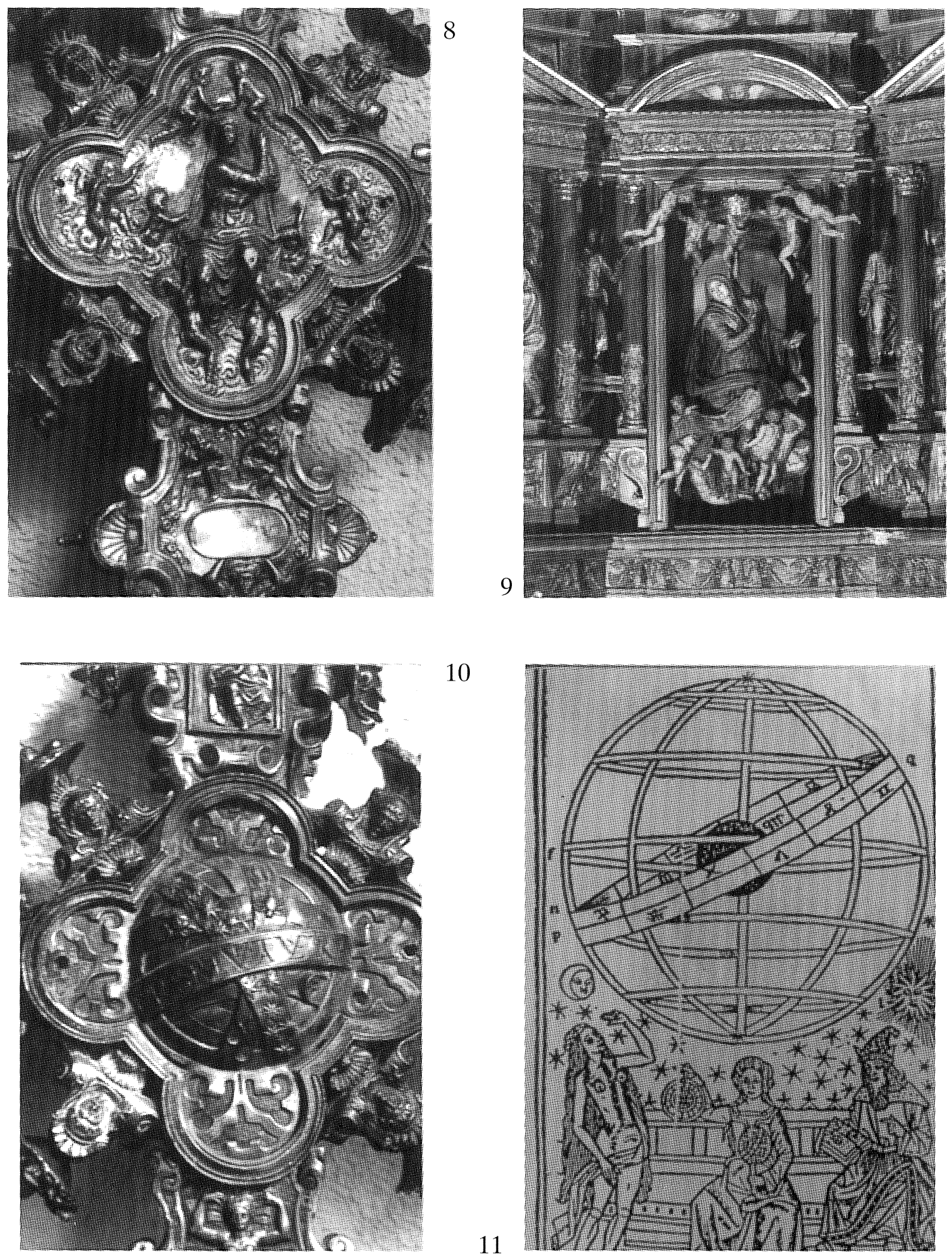

10

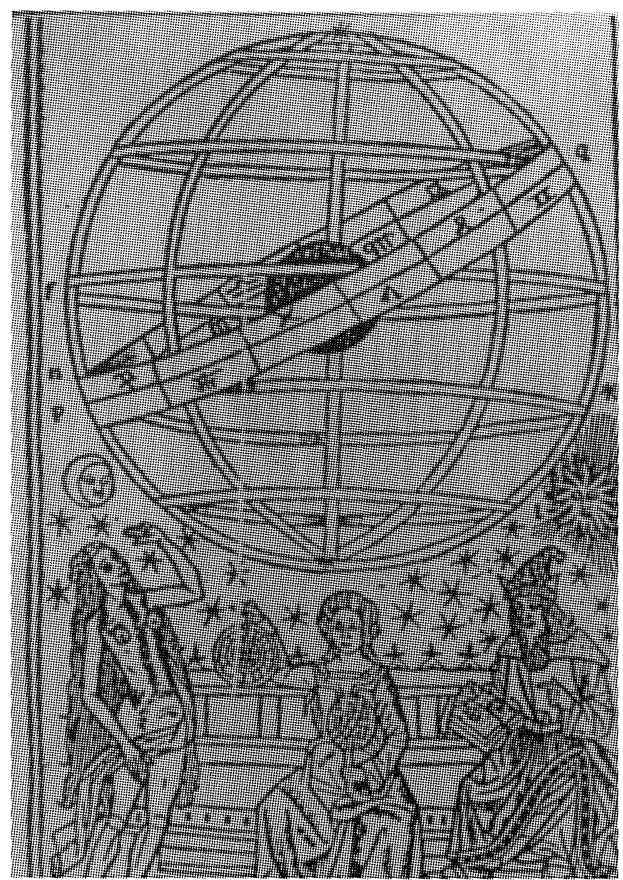

Figura 8, 9, 10 y 11. Cruz de Santorcaz. Asunción-Coronación. Estado actual. G. Becerra. Asunción-Coronación del Retablo de Astorga. Cruz de Santorcaz. Estado actual. Esfera armilar en el Opusculum de Sphera Mundi. Alcalá, 1526. 
La propia inscripción de la esfera armilar alude al hecho de la muerte de Cristo como garantía de salvación eterna. Incluso las imágenes del sol y la luna, elementos habituales en las cruces de plata, donde suelen enmarcar la cabeza de Cristo, adquieren en la cruz de Santorcaz un sentido astrológico al representarse sus caminos por separado. Tampoco se sigue el orden convencional en los signos del zodíaco, ya que la secuencia correcta en la revolución aparente desde la Tierra sería, en primer lugar, la aparición de Libra, luego Escorpión y, mucho más tarde, detrás de Sagitario, Capricornio y Acuario, Piscis. Pero en el relieve de Santorcaz Piscis se encuentra intencionadamente junto a Escorpión.

Además el Sol está situado al norte del Ecuador y de la Eclíptica, es decir, en la Primavera. La Luna al sur, opuesta, es decir en Luna llena, y el Ecuador y la Eclíptica se cruzan a la altura de Libra o lo que es igual en el equinoccio de Otoño. La Luna llena y la Primavera es la época de la muerte de Cristo. Por otra parte, Piscis es el signo tradicionalmente asociado a Cristo, no sólo en cuanto a época - la era de Piscis - sino en cuanto a carácter y a su propio nombre, ya que las letras que lo componen forman un acróstico que se interpreta como Jesucristo Hijo de Dios Salvador y que significan pez en griego. Además, la ubicación concreta de Piscis en el límite del horizonte alude también a Cristo que murió cuando este signo estaba en el ocaso. En cuanto a la Luna llena, está en el signo de Libra, según Cardan, el día de la muerte de Cristo, es decir, pasados treinta y tres años desde su situación en el Ascendente del Nacimiento ${ }^{26}$. Por último, Escorpión es el Bajo Cielo de la muerte y puede aludir, según el profesor Esteban Lorente, al Descenso al Limbo, aunque Cardan no lo cita.

La manzana de la cruz (Fig. 4) simula un templete de planta circular con dos cuerpos decrecientes articulados por parejas de columnas jónicas, que apoyan sobre pedestales salientes y culminan en entablamento quebrado con remates piramidales ${ }^{27}$. Los fustes del cuerpo bajo son acanalados y llevan paños colgantes en su tercio superior, mientras que los del cuerpo alto son lisos. En las cajas rectangulares del cuerpo bajo se reproducen cuatro escenas de la Pasión: Oración en el Huerto, Flagelación, Coronación de Espinas y Cristo con la Cruz a Cuestas (Figs. 12-15). Entre ellas, en los intercolumnios correspondientes, se desarrollan cuatro inscripciones latinas alusivas también a la Pasión y recogidas de las Sagradas Escrituras: 1.- NON/ MEA/ VOL/VN/ TAS/ SED/ TVA/ FIAT (Lucas, 22, 42); 2.- SIE/ STD/ OLO/ RSI/ CVT/ MEV/ S. (Jeremías, Lamentaciones, 1, 12); 3.- PRO/ NOB/ IS.[T/RA] DI/ DIT/ ILL/VM./ (San Pablo, Rom., 4, 25); 4.- CVM/ INI/ QVS/ REP/ VTA/ TVS/EST (Isaías, 53, 12 y Lucas, 22, 37) ${ }^{28}$. La segunda y la tercera están incorporadas en los «Responsorios del Viernes Santo», y a esta última Tomás Luis de Vitoria puso música pocos años después de la ejecución de la cruz ${ }^{29}$. El cuerpo superior alberga las figuras del apostolado, alternando parejas en cajas rectangulares, con figuras aisladas bajo arcos de medio punto. La estructura

26 Además J. F. Esteban Lorente: «1186, Horóscopo del Triunfo de Yavé (Apocalipsis XIX)», IX Congreso Ibérico de Astrología, Poio, 1992, p. 48, hace referencia a Libra como signo de Justicia, referido al Juicio Final y a Cristo como Sol de Justicia según San Mateo.

27 Además de Brasas, recientemente la ha incluido E. Wattenberg García en «Bellas Artes», Guía. Museo de Valladolid, Valladolid, 1997, p. 227, a quien agradecemos las facilidades que nos ha dado para fotografiar y estudiar esta pieza.

${ }^{28}$ La traducción sería: 1- «No se haga mi voluntad sino la tuya». 2- «En verdad que no hay dolor como el mío». 3- «Lo entregó por nosotros» (Creemos que la transcripción correcta debe ser «...[T/RA]DIDIT...» en lugar de «... T/VI DIDIT...» como se ha venido transcribiendo hasta ahora ). 4- «Fue contado entre los malhechores».

29 Breviarium romanum ex decreto sacro-sancto Concilii Tridentini restitutum... Pio V..., Madrid, 1770, pp. 321, 339, 344 y 346. C. Gallico: «La Época del Humanismo y del Renacimiento» en Historia del la Música, 4, Madrid, 1991, p. 75, menciona la composición «O vos omnes» que es el comienzo de una de las frases de la cruz de Santorcaz, a la que Victoria puso música. 

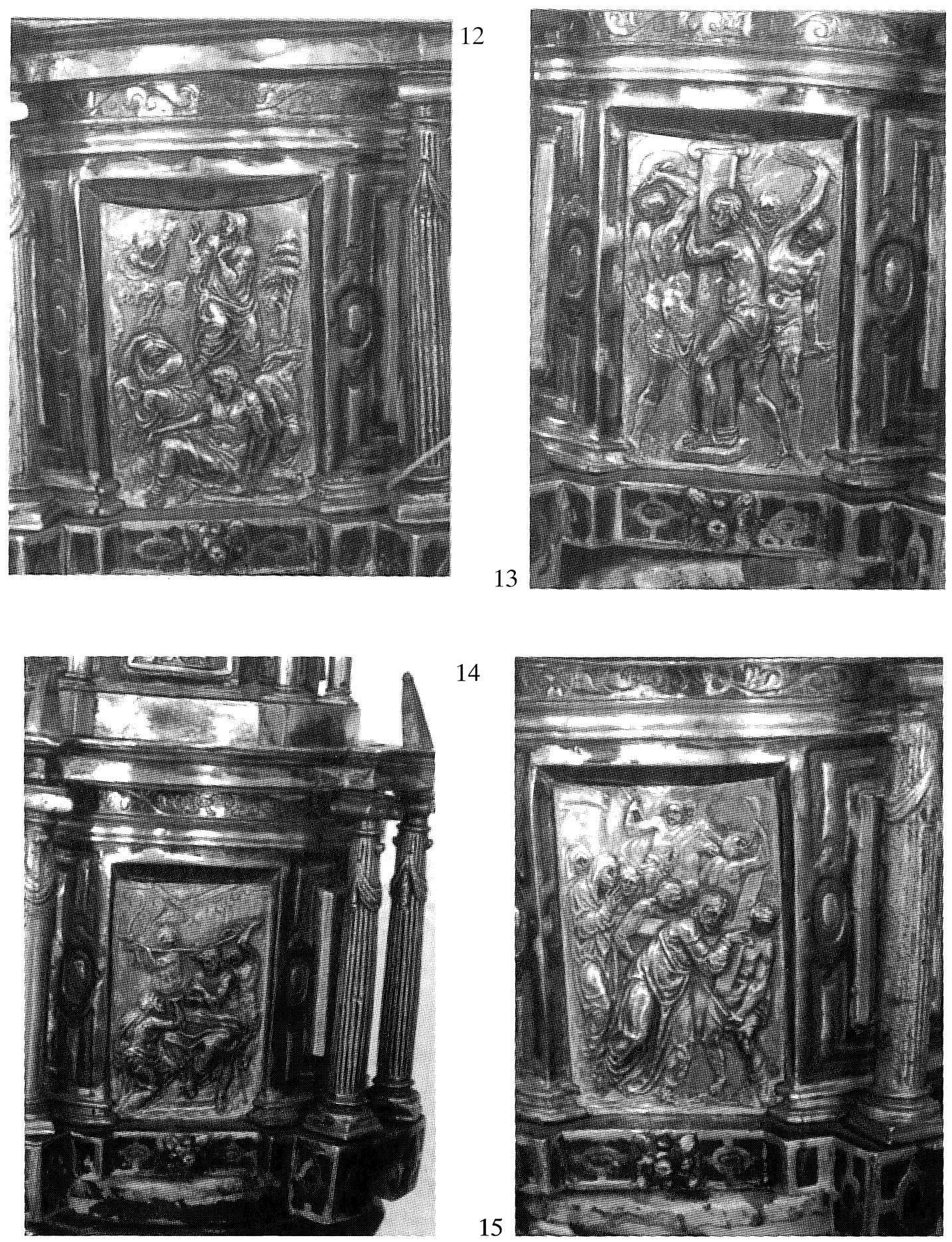

Figuras 12-15. Cruz de Santorcaz. Relieves de la manzana. Estado actual. 
descansa sobre un mango cilíndrico, rematado por un grueso toro, todo ello cubierto por una decoración a base de cartelas, cabezas de carnero y máscaras con tocados de plumas. Otras cartelas, espejos y frutos decoran también el remate de la pieza y la espiga donde encajaría el árbol de la cruz.

El diseño del templete revela el conocimiento de la ya citada cruz de Valdeavero, aunque Guzmán utiliza el orden jónico en los dos cuerpos y sustituye los frontones que Marcos Hernández dispuso como remates de las columnas por pirámides herrerianas. La sobriedad y monumentalidad de la traza evocan, por otra parte, las de la mazonería del retablo de Las Descalzas Reales de Madrid con el que coincide en el formato rectangular de las cajas y en el diseño de los fustes, salvo por la utilización de estrías rectas en lugar de torsas. Con Becerra hay que relacionar también los relieves figurativos, de fuertes anatomías romanistas, poses rebuscadas y composiciones compactas, bien ajustadas a los respectivos marcos e inspiradas, en último término, en tipos y actitudes miguelangelescos interpretados por Pierino del Vaga y Daniel de Volterra, artistas con los que Becerra contactó y trabajó en Roma ${ }^{30}$.
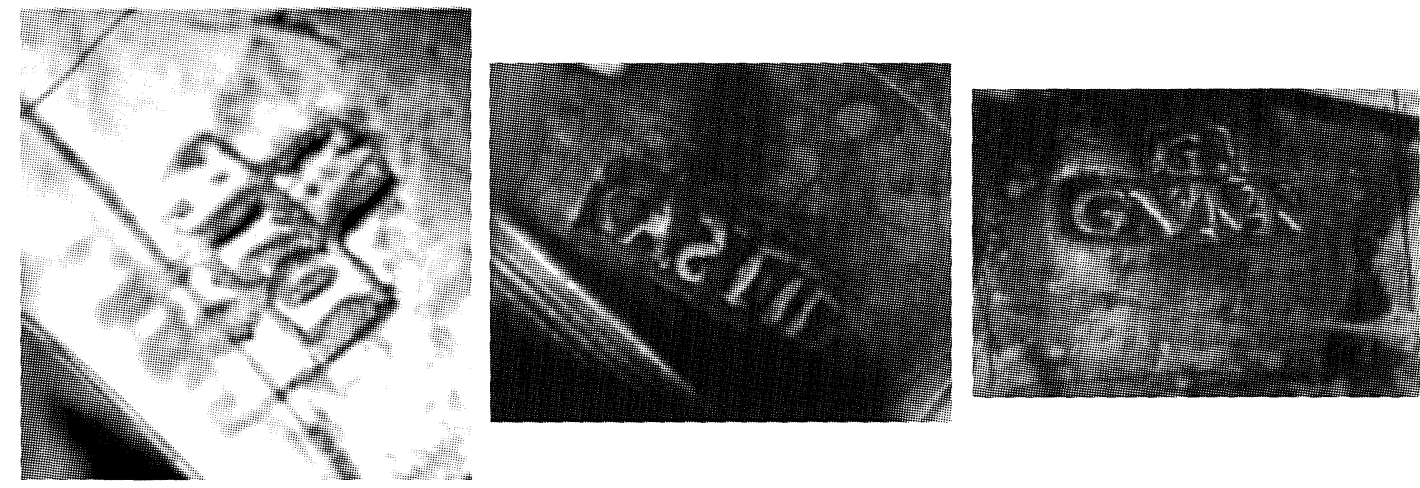

Figura 16. Cruz de Santorcaz. Marcas de la manzana. Estado actual.

Las marcas están impresas en la base del cuerpo superior (Fig. 16). La de localidad de Alcalá es la habitual por estas fechas, con el castillo sobre el nombre de la villa en caracteres góticos partido en dos líneas. La del marcador (CASTIL, con la S invertida) pertenece, quizás, a Gaspar del Castillo y la tercera (G/GVZMAN, con la Z dentro de la V y la $\mathrm{M}$ y la A unidas) es la personal de Gaspar de Guzman, artífice de la pieza.

Tanto por su excelente calidad como por el carácter romanista de los relieves, la manzana se asemeja al árbol de la cruz, con el que también concuerda por sus dimensiones ${ }^{31}$, como partes pertenecientes a un mismo conjunto. La misma unidad se advierte en el programa iconográfico que desarrolla el tema de la Pasión y Muerte de Cristo, comenzando por las cuatro escenas del nudo y culminando y resaltando esta última mediante la inclusión del horóscopo. La presencia de los Apóstoles y Evangelistas está justificada por el papel que desempeñaron como difusores de la Doctrina y fundadores de las primitivas sedes episcopales, labor semejante a la que los siete Varones Apostólicos, incluido San Torcuato, natural de

30 M. Calí: De Miguel Ángel a El Escorial..., pp. 285 y ss.

${ }^{31}$ En su estado actual la cruz mide $71 \times 59 \mathrm{cms}$. y la manzana $41 \times 19 \mathrm{cms}$ 
Santorcaz, desarrollaron en la Península Ibérica. La Asunción-Coronación de la Virgen quizás aludiera a la primitiva advocación del templo hasta el año 1583, pero, en cualquier caso hay que relacionarla con María, Reina de los Cielos por su calidad de Madre del Redentor y, por ello mismo, «Fuente y origen de los bienes» derivados del hecho de la Redención, según se indica en la inscripción bajo sus pies. El tema de la Imposición de la Casulla a San Ildefonso resultaba casi obligado en una iglesia directamente dependiente del arzobispado de Toledo. Por último, las restantes inscripciones son como el hilo conductor del programa que informan al espectador en paralelo a las propias imágenes y refuerzan su significado apoyándose en los textos sagrados.

Es obvio que un programa tan elaborado y un desarrollo tan brillante no se debe ni a la casualidad ni tan sólo a la simple pericia de un platero. Gaspar de Guzmán se limitaría a traducir, aunque magistralmente, las indicaciones de un mentor culto, versado en Teología y en Astrología e interesado también en exaltar la figura de San Torcuato como difusor de la historia de la Pasión y Muerte de Cristo, quizás con el ánimo de contribuir al desarrollo del culto a los santos, máxime si se trataba de santos locales, defendido por el Concilio de Trento como medio de acercarse a los fieles.

No tenemos constancia documental de este desconocido bienhechor de Santorcaz. Pero en el contexto de la archidiócesis de Toledo de la segunda mitad del siglo XVI podemos apuntar alguna hipótesis razonable. No hay dudas de que la obra se hizo por cuenta de la propia parroquia, puesto que los pagos se recogen en el citado Libro de Fábricas. Sin embargo, el elevado costo de la cruz, cuyo último plazo ascendió a la cantidad de treinta y dos mil doscientos cincuenta maravedís, demuestra que se labró previa licencia del visitador y con el beneplácito del Consejo de Gobernación del arzobispado. Tales eran los requisitos imprescindibles para todas aquellas piezas de importe superior a los veinte mil maravedís que se ejecutasen en la archidiócesis de Toledo según las Constituciones Sinodales del cardenal Gaspar de Quiroga de 1582 en funcionamiento desde años atrás ${ }^{32}$.

Ni Quiroga, nombrado cardenal en 1577 cuando ya estaba terminada la cruz, ni Bartolomé de Miranda y Carranza, su antecesor en el cargo desde 1558 pero ausente de Toledo desde 1559 en que fue prendido y procesado por la Inquisición, pudieron responsabilizarse de esta obra ${ }^{33}$. El seguimiento y revisión de la misma habría que relacionarlo, quizás, con la figura de Sancho Busto de Villegas, natural de Ocaña y miembro de la Suprema Inquisición, que fue nombrado gobernador de Toledo «en lo espiritual y en lo temporal», en ausencia de Carranza y tras la muerte del gobernador Gómez Téllez Girón, el diecinueve de agosto de 1569 y que permaneció en el cargo hasta abril de $1576^{34}$. Aunque desconocemos los pormenores de su biografía, es evidente que la importancia de los puestos que desempeñó permiten suponer que su cultura y su interés por la iconografía religiosa pudieron impulsarlo a patrocinar el programa de la cruz, afinando en el tema del horóscopo para marcar los límites entre la herejía y la ortodoxia en un asunto que en estos momentos era extraordinariamente delicado y que él, como miembro de la Inquisición y con profundos conocimientos teológicos, podía claramente delimitar.

32 Información recogida por J. M. Cruz Valdovinos: «Platería madrileña del siglo XVI», Madrid en el Renacimiento, Madrid, 1986, p. 259.

${ }_{33}$ Una síntesis de la biografía de ambos prelados en las voces correspondientes del Diccionario de Historia Eclesiástica de España, Madrid, 1972, vol. I, pp. 358-361 y vol. III, pp. 2.041-2.042.

${ }^{34}$ J. Román de la Higuera: Historia eclesiástica de la imperial ciudad de Toledo. MS. 1.293 de la Biblioteca Nacional. 
Recordemos que, de acuerdo a las disposiciones del Concilio de Trento, en 1570 y en 1583 se publicaron en España sendos índices impulsados por Felipe II y por el cardenal Quiroga, respectivamente, y que en ambos se expurgaron muchos textos astrológicos, algunos párrafos de Cardan inclusive ${ }^{35}$. En este ambiente y en un lugar próximo a Toledo y dependiente directo del arzobispado, el programa de la cruz de Santorcaz, hecha en 1576, debió de ser elaborado cuidadosamente en todos sus detalles por un experto para garantizar su ortodoxia. Pudo ser el propio gobernador, pero no hay que descartar la colaboración del propio Quiroga que, poco después, realizaría un profundo expurgo de libros astrológicos cuando era inquisidor general.

En resumidas cuentas, la cruz de Santorcaz es una obra excelente y documentada del platero complutense Gaspar de Guzmán, que terminó de cobrarla en 1577. Aunque se creía desaparecida, se encuentra hoy dispersa entre los museos de Valladolid (manzana) y de Santa Cruz de Toledo (árbol). Su estilo conecta con el del platero complutense Marcos Hernández, por una parte, y con la retablística y escultura romanista contemporánea, por otra, apreciándose estrechas semejanzas con obras de Gaspar Becerra en Astorga y Descalzas Reales de Madrid. Además, su programa iconográfico la convierte en pieza única y singular en el conjunto de la platería española contemporánea al incluir entre las escenas habituales de la Pasión las imágenes de los Siete Varones Apostólicos y, sobre todo, el tema del horóscopo de la Muerte de Cristo, de gran rareza iconográfica en todo el arte español del quinientos. Respecto de su posible mentor, dada la complejidad y lo delicado del programa en unos momentos en que la astrología estaba en entredicho, creemos debió ser un alto eclesiástico, versado en iconografía sagrada y próximo a la Inquisición hasta el punto de poder elaborar el horóscopo con todas las garantías a nivel de ortodoxia. En este ambiente, la figura más idónea pudo ser el licenciado don Sancho Busto de Villegas, gobernador del arzobispado de Toledo, bien solo o bien con la ayuda de don Gaspar de Quiroga cuando aun no era cardenal.

35 J. F. Esteban Lorente: «La Naturaleza Humana...», p. 264, recoge la regla novena del Index et catalogus librorum prohibitorum... de Gaspar de Quiroga, de 1583. Un ejemplar se conserva en la B.N. R/28254. El mismo espíritu preside el Index librorum prohibitorum... publicado por el arzobispo de Lisboa don Jorge Dalmeida en 1581. Hemos manejado el ejemplar de la B.N. U/7821. 